\title{
Use of genetic markers for the detection of off-types for DUS phenotypic traits in the inbreeding crop, barley
}

\author{
Benedetta Saccomanno • Margaret Wallace • \\ Donal M. O'Sullivan • James Cockram (D)
}

Received: 3 May 2019 / Accepted: 6 December 2019/Published online: 10 January 2020

(C) The Author(s) 2020

\begin{abstract}
Detection of crop off-types is of interest for multiple uses, including the assessment of uniformity for new plant variety applications during distinctness, uniformity and stability (DUS) testing for the awarding of plant breeders' rights (PBR). Here, we investigate whether genetic markers, in this case Kompetitive Allele-Specific PCR (KASP), can be used for the identification off-types for phenotypes assessed for DUS in the inbreeding cereal crop, barley (Hordeum vulgare). To demonstrate proof of principle, KASP markers diagnostic for phenotypic expression of nine DUS phenotypes, and DNA from two barley varieties ('Pelican' and 'Felicie') carrying contrasting alleles at each marker were used. We found that for the majority of markers, it was possible to robustly call alleles down to template DNA concentrations of $2 \mathrm{ng}$, but not $\leq 0.2 \mathrm{ng}$. When used in mixtures of DNA consisting of 'Felicie' DNA spiked with different concentrations of 'Pelican' DNA,
\end{abstract}

Electronic supplementary material The online version of this article (https://doi.org/10.1007/s11032-019-1088-y) contains supplementary material, which is available to authorized users.

B. Saccomanno $(\bowtie) \cdot$ M. Wallace $\cdot$ J. Cockram $(\bowtie)$

NIAB, Huntingdon Road, Cambridge CB3 0LE, UK

e-mail: benedetta.saccomanno@niab.com

e-mail: james.cockram@niab.com

Present Address:

D. M. O’Sullivan

School of Agriculture Policy and Development, University of Reading, Whiteknights, PO Box 217, Reading RG6 6AH, UK robust allele calling was possible in DNA mixtures down to $18 \mathrm{ng}: 2 \mathrm{ng}$. Collectively, this demonstrates that where diagnostic markers are available, molecular identification of a single off-type for a given DUS trait within a bulk of ten individuals should be possible. We validated this assumption, with all of the diagnostic genetic markers investigated found to robustly detect DUS off-types at a frequency of $10 \%$ in DNA extracted from tissue collected from pools of 10 individuals. Ultimately, this work demonstrates that, where diagnostic polymorphisms are known for DUS traits, KASP markers should be able to robustly detect off-types or cross-contamination within DNA samples from a diploid inbred species down to $10 \%$. While just two varieties that contrasted for the eight DUS targeted were investigated in this study, as the markers used are diagnostic for their relevant phenotype (or a proportion of the variation observed for that phenotype), in theory the approach should be valid for any variety studiedalthough the introduction of novel alleles via spontaneous mutation or more exotic germplasm pools may mean that marker sets would need to be periodically added to or updated. However, we nevertheless demonstrate the principle that, for a subset of DUS traits, molecular markers can now be robustly used as a tool towards determining all three components of the DUS testing process in barley. These results are relevant for the assessment of varietal uniformity by crop breeders, crop testing authorities and germplasm maintenance, as well as highlighting the potential use of bulk samples rather than individual plant samples for assessment of distinctness by molecular methods. 
Keywords Hordeum vulgare - Diagnostic genetic markers - Distinctness uniformity and stability traits . Plant breeders' rights - Variety protection . SNP genotyping $\cdot$ Plant variety protection

\section{Introduction}

The diploid inbreeding crop species barley (Hordeum vulgare L.) is one of the world's most important cereal crops. The development of new barley varieties with improved performance takes around 10 years, requiring considerable investment by crop breeders. The awarding of Plant Variety Protection (PVP) allows breeding companies to protect the investment they make in the development of new crop varieties. The rules under which PVP is granted are governed by the International Union for the Protection of New Varieties of Plants (UPOV). Currently, seventy-five countries or intergovernmental agencies are signatories of the UPOV Convention. These members all acknowledge the breeders of new varieties of plants by granting them intellectual property rights, based on the varietal submissions being: 1 . New, i.e. not commercialised before. 2. Distinct (D) from existing varieties. 3. Uniform (U), i.e. sufficiently uniform in the phenotypic traits with which D is assessed. 4. Stable (S), i.e. the phenotypic traits assessed remain unchanged after repeated propagation (UPOV Convention Articles 5-9 (UPOV 1991)). The system used to establish distinctness, uniformity and stability is known as DUS testing. In line with the test guidelines agreed by UPOV members (UPOV TG/ 19/10), barley DUS testing involves phenotypic evaluation of 28 traits (Supplementary Table 1), undertaken over two separate growing seasons. Due to the requirement of all new varieties to be $\mathrm{D}, \mathrm{U}$ and $\mathrm{S}$, irrespective of how well they perform agronomically, breeding companies are interested in using genetic markers to help ensure their candidate varieties meet the DUS criteria that are necessary for them to ultimately be released as commercial varieties protected by PVP. Using 500 barley varieties, combined with phenotypic data for all 28 barley DUS traits and a 1500 feature single nucleotide polymorphism (SNP) array, we previously undertook genome-wide association scans (GWAS) for barley DUS traits, identifying genetic loci controlling many of the phenotypes investigated (Cockram et al. 2010). For a selected trait (the presence or absence of the pigment anthocyanin), we demonstrated that GWAS could be used to fine-map genetic loci controlling DUS traits. Anthocyanin presence/absence was found to be controlled by the ANTHOCYANINLESS 2 (ANT2) locus, with GWAS delimiting a physical region that contained three genes, including a strong candidate gene encoding a basic helix-loop-helix (bHLH) domain protein. Population resequencing showed that all varieties that lacked anthocyanin pigmentation carried a $16 \mathrm{bp}$ deletion resulting in a truncation of the predicted protein upstream of the bHLH domain.

The genes and allelic variants controlling three other barley DUS traits are also known. (1) Two major loci control the DUS trait 'seasonal type' (UPOV character 29): VERNALIZATION-H1 (VRN-H1) and VRN-H2. Intronic deletions within $V R N-H 1$ are thought to confer the mutant vernalisation insensitive 'spring' alleles (Cockram et al. 2007a, b, 2009; Szücs et al. 2007; Hemming et al. 2009; Trevaskis 2010), while deletions spanning three duplicated genes (ZCCT-Ha, $-\mathrm{Hb},-\mathrm{Hc}$ ) confer mutant vernalisation insensitive 'spring' alleles at $V R N-H 2$ (Yan et al. 2004; Karsai et al. 2005; Distelfeld et al. 2009). Barley varieties with the 'alternative' seasonal type, which can be sown as either winter or spring types, have characteristic allelic combinations at $V R N-H 1, V R N$ H2 and a third locus, PHOTOPERIOD REPSPONSE-H2 (PPD-H2) (Cockram et al. 2015). (2) Two genes controlling the trait 'ear: number of rows' (UPOV 13) have been map-based cloned. Depending on whether the two lateral spikelets at each floret are infertile (wild type) or fertile (mutant), barley varieties are described as 2- or 6-rowed, respectively. Mutations at the $\mathrm{HvHOX1}$ gene underlying the VRS1 locus result in a 6-row phenotype (Komatsuda et al. 2007), while partial filling of lateral spikelets is controlled by allelic variation at the TEOSINTINE BRANCED 1 (TB1) gene at the INTERMEDIUM-C (INT-C) locus (Ramsay et al. 2011). (3) DUS trait 'grain: disposition of lodicules' (UPOV 27) is controlled by the CLYSTOGAMY 1 (CLY1) locus, with mutations in the underlying $H v A P 2$ transcription factor shown to result in closed flowering due to the failure of lodicules to expand (Nair et al. 2010). As well as these cloned genes, four additional major genetic loci likely control the barley DUS traits identified by Cockram et al. (2010): HAIRY LEAF SHEATH 1 (HSH1, Lundqvist et al. 1996) for trait 'lowest leaves: hairiness of leaf sheaths' (UPOV 2), SHORT RACHILLA HAIR (SRH, Franckowiak 1995) for 'grain: rachilla hair type' (UPOV 22), TOOTHED LEMMA 1 (GTH1, Lundqvist et al. 1997) for 'grain: speculation of inner lateral nerves of dorsal side of lemma' (UPOV 25), 
and $B L X$ (Lundqvist et al. 1996) for 'kernel: colour of aleurone layer' (UPOV 28).

The potential use of molecular markers within the DUS context is a source of ongoing consideration and debate (recently reviewed by Jamali et al. 2019). Diagnostic Kompetitive Allele-Specific PCR (KASP) markers for all of cloned genes controlling DUS traits, along with the major genetic loci identified by GWAS (Cockram et al. 2010), have previously been validated (Cockram et al. 2012). However, while these were shown to be able to discriminate between homozygous alleles (and therefore of use for the assessment of D and S), their ability to detect contrasting alleles in admixed DNA samples (i.e. the assessment of $U$ ) has not been determined. Here we investigate the possibility of using molecular approaches for the detection of DUS offtypes in an inbreeding diploid crop species, using KASP markers diagnostic for allelic variation diagnostic for, or contributing to the control of, eight barley DUS traits. The DUS KASP markers tested were predominantly found to be sensitive down to concentrations of $2 \mathrm{ng}$, and all were able to robustly detect single off-types in template DNA extracted from 10 pooled individuals, indicating assessment of uniformity in the DUS context should be possible where the diagnostic polymorphisms underlying the targeted trait are known. The results are discussed with reference to DUS assessment and the release of new crop varieties.

\section{Methods}

Germplasm and plant growth

The barley varieties 'Felicie' (Application For Protection, AFP, number 2/1091) and 'Pelican' (AFP 2/2077) were sourced (with appropriate permission) from germplasm stocks maintained at NIAB. Seeds were sown in 96-well trays using M2 potting and bedding compost (ICL Levington Advance), and grown in a heated glasshouse, with $16 \mathrm{~h}$ light photoperiod maintained using supplemental lighting. DUS phenotypic data for these two varieties was sourced from their publicly available varietal descriptions.

DNA template preparation

Genomic DNA was extracted from young leaf material following the Tanksley protocol (Fulton et al. 1995), with the inclusion of $60 \mu \mathrm{l}$ RNase A (Qiagen) in the microprep buffer. DNA quantity and quality were determined using a Nanodrop 200 spectrophotometer (Thermo Scientific). Starting DNA concentrations was standardised and subsequently used for: (1) serial dilutions, using PCR grade double-distilled water (SigmaAldrich), (2) generation of artificially admixed DNA samples, by mixing 'Felicie' and 'Pelican' DNAs in different proportions, to a total concentration of $20 \mathrm{ng} /$ $\mu \mathrm{l}$. Additionally, bulk DNA extractions were undertaken by sampling leaf material bulked from 10 individual plants $(0.3 \mathrm{~cm}$ long $\times 0.5 \mathrm{~cm}$ wide per plant), with the proportion of 'Felicie' to 'Pelican' tissue samples in the bulk varying as shown in Supplementary Table 2. The concentration of each bulk DNA sample was standardized to $20 \mathrm{ng} / \mu \mathrm{l}$ using PCR grade double-distilled water.

\section{Genotyping}

SNP genotyping was undertaken using previously described KASP markers (Cockram et al. 2012) that assay genetic loci diagnostic for nine DUS phenotypes, as identified by Cockram et al., (2010): Hv11_11299_GC (trait 'lowest leaves: hairiness of leaf sheaths'), HvOs03g14380_G125A ('kernel: colour of aleurone layer'), HvCly1_A2604G ('grain: disposition of lodicules'), HvANT2_C4289T ('anthocyanin pigmentation'), HvVRNH1_SNP2 ('seasonal habit'), HvPPDH1_A2721G ('long-day photoperiod response'), HvOs02g01490_G607A ('grain: hairiness of ventral furrow'), Hv11_10933_GC ('sterile spikelet attitude') and Hv11_10818_CA ('grain lateral nerve spiculation'). KASP primer sequences are listed in Supplementary Table 3 . For each assay, reaction volumes were $2.5 \mu$ KASP V4.0 2× Master Mix (LGC Biosciences), $0.07 \mu \mathrm{l}$ KASP primer mix (see Supplementary Table 4) and $2.5 \mu$ DNA template (or 2.5 $\mu$ l PCR-grade water for negative controls). Genotyping was carried out using a ProFlex PCR System Thermocycler (Applied Biosystems) using the following conditions: 1 cycle at $94{ }^{\circ} \mathrm{C}$ for $15 \mathrm{~min} ; 10$ cycles at $94^{\circ} \mathrm{C}$ for $20 \mathrm{~s}, 65^{\circ} \mathrm{C}$ for $60 \mathrm{~s}$ with a touchdown of $-0.8{ }^{\circ} \mathrm{C} /$ cycle to $57{ }^{\circ} \mathrm{C}$; 35 cycles at $94{ }^{\circ} \mathrm{C}$ for $20 \mathrm{~s}, 57^{\circ} \mathrm{C}$ for $60 \mathrm{~s}$; final hold at $10^{\circ} \mathrm{C}$. Fluorescence of VIC and FAM fluorophore $5^{\prime}$ end labelled PCR products were subsequently read using a Scientific QuantStudio ${ }^{\text {TM }} 12$ K Flex real-time PCR System (Thermo Fisher Scientific). ROX was used as a passive fluorescent reference to allow normalisation of variations in signal caused by differences in well-to- 
well liquid volume, following the manufacturer's instructions (LGC Genomics). Four technical replicates were assayed for each DNA sample used. Results were visualised using SNP Viewer v2 (LGC Genomics) or with Excel (Microsoft).

\section{Results}

Barley varieties, DUS trait scores and diagnostic genetic markers

In order to investigate the ability and sensitivity of genetic markers to detect DUS off-types in barley, two UK varieties were selected that differed in their phenotypes for eight DUS traits for which relevant diagnostic or perfect genetic markers were available: 'Felicie' and 'Pelican'. The DUS traits and phenotypic state for each variety, along with details of the relevant KASP genetic markers, are listed in Table 1.

Limits of diagnostic genetic marker sensitivity

To determine the lower limits of template DNA concentration at which the diagnostic genetic markers selected for study were able to robustly call SNPs, six 1-in-10 serial dilutions of 'Felicie' and 'Pelican' DNAs were made, starting with stock DNA at $20 \mathrm{ng} / \mu \mathrm{l}$, with dilutions of 2, 0.2, 0.02, 0.002, 0.0002 and $0.00002 \mathrm{ng} / \mu \mathrm{l}$. These were used as templates for KASP genotyping reactions with the nine diagnostic genetic markers (Fig. 1). Six KASP markers showed robust calling (i.e. clearly distinguishable from the negative water controls) with template concentrations of 2 ng (i.e. 1-in-10 DNA dilutions: Hv11_11299_GC, HvANT2_C4289T, Hv 11 1_0933_GC, Hv 11 _ 10818 C A, HvOs02g01490_G607A and HvVRNH1_SNP2; Fig. $1 \mathrm{~b}, \mathrm{c}, \mathrm{e}-\mathrm{g}, \mathrm{i})$. For the remaining three markers, robust calls at template concentrations down to $2 \mathrm{ng}$ were only possible for one of the two alleles, as at this template level HvOs03g14380_G125A (relevant to DUS phenotype 'Kernel: colour of aleurone layer') could not clearly call 'Felicie' alleles, while HvPPDH1_A2721G ('Time of ear emergence') and HvCly1_A2604G ('Grain: disposition of lodicules') could not clearly call 'Pelican' alleles (Fig. 1).

\section{Detection of DUS off-types via in vitro admixture}

Having determined the sensitivity limits of the diagnostic genetic markers selected for study to call alleles in the presence of template DNA from a single variety, the

reliably call alleles at different template DNA concentrations are indicated. Fluorophores: V = VIC, F = FAM. *Allele-specific KASP primers assay base on opposite DNA strand. ${ }^{\dagger}$ Strongly.

\$Long day (16 h daylight) photoperiod sensitivity
Table 1 Genetic markers used to predict DUS phenotypes, along with information describing phenotypic trait expression and KASP allele for the two barley varieties investigated ('Felicie' and 'Pelican'), which contrast for all of the eight DUS phenotypes assessed via diagnostic genetic markers here. The limits of the assay to

\begin{tabular}{|c|c|c|c|c|c|c|c|}
\hline DUS trait & $\begin{array}{l}\text { CPVO } \\
\text { Trait } \\
\text { No. }\end{array}$ & KASP marker & $\begin{array}{l}\text { Trait } \\
\text { expression } \\
\text { Felicie }\end{array}$ & $\begin{array}{l}\text { Felicie allele } \\
\text { (fluorophore) }\end{array}$ & $\begin{array}{l}\text { Trait } \\
\text { expression } \\
\text { Pelican }\end{array}$ & $\begin{array}{l}\text { Pelican allele } \\
\text { (fluorophore) }\end{array}$ & $\begin{array}{l}\text { Sensitivity limit } \\
\text { of marker } \\
\text { (ng DNA) }\end{array}$ \\
\hline $\begin{array}{l}\text { Kernel: colour of } \\
\text { aleurone layer }\end{array}$ & 1 & HvOs03g14380_G125A* & Whitish & $\mathrm{C}(\mathrm{F})$ & Coloured $^{\dagger}$ & $\mathrm{T}(\mathrm{V})$ & $<20>2$ \\
\hline Hairiness of leaf sheaths & 3 & Hv11_11299_GC & Absent & $\mathrm{G}(\mathrm{V})$ & Present & $\mathrm{C}(\mathrm{F})$ & 2 \\
\hline $\begin{array}{l}\text { Auricle anthocyanin } \\
\text { colouration }\end{array}$ & 4 & HvANT2_C4289T & Absent & $\mathrm{C}(\mathrm{F})$ & Very strong & $\mathrm{T}(\mathrm{V})$ & 2 \\
\hline Time of ear emergence & 7 & HvPPDH1_A2721G & Insensitive $^{\$}$ & $\mathrm{~A}(\mathrm{~F})$ & Sensitive $^{\$}$ & $\mathrm{G}(\mathrm{V})$ & $<20>2$ \\
\hline Sterile spikelet: attitude & 20 & Hv11_10933_GC & Divergent & $\mathrm{C}(\mathrm{V})$ & Parallel & $\mathrm{G}(\mathrm{F})$ & 2 \\
\hline $\begin{array}{l}\text { Grain: speculation of } \\
\text { lateral nerves }\end{array}$ & 25 & Hv11_10818_CA & Absent & $A(F)$ & Medium & $\mathrm{C}(\mathrm{V})$ & 2 \\
\hline $\begin{array}{l}\text { Grain: hairiness of } \\
\text { ventral furrow }\end{array}$ & 26 & HvOs02g01490_G607A & Present & $\mathrm{A}(\mathrm{V})$ & Absent & $\mathrm{G}(\mathrm{F})$ & 2 \\
\hline $\begin{array}{l}\text { Grain: disposition } \\
\text { of lodicules }\end{array}$ & 27 & HvCly1_A2604G & Frontal & $\mathrm{G}(\mathrm{V})$ & Clasping & $\mathrm{A}(\mathrm{F})$ & $<20>2$ \\
\hline Seasonal growth type & 28 & HvVRNH1_SNP2 & Spring & $\mathrm{G}(\mathrm{V})$ & Winter & $\mathrm{A}(\mathrm{F})$ & 2 \\
\hline
\end{tabular}



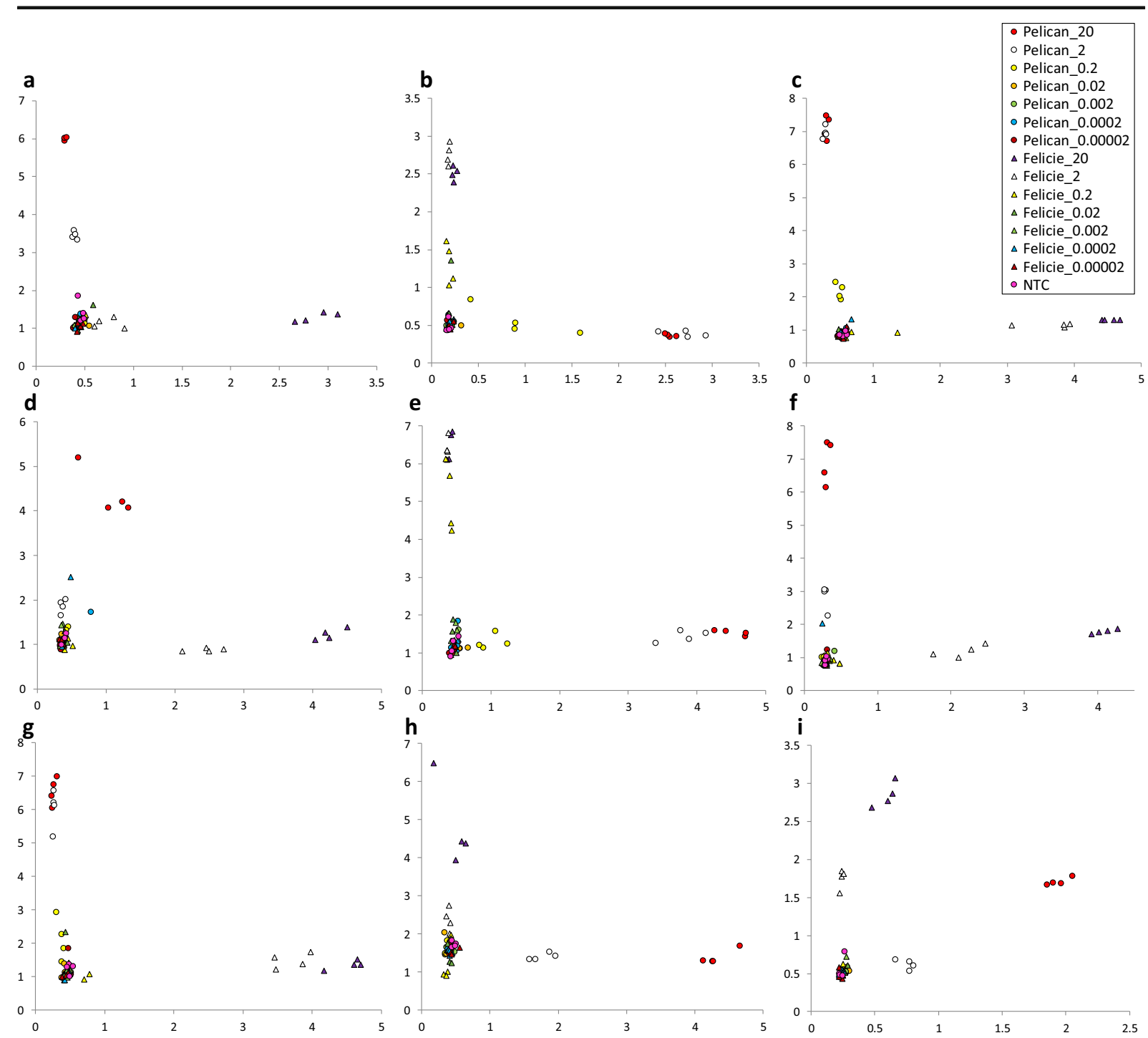

Fig. 1 Assessment of genetic marker diagnostic for DUS traits for sensitivity across a serial dilution of DNA template concentrations. DNAs extracted from barley cultivars 'Felicie' and 'Pelican', which contrast for all of the eight DUS phenotypes assessed via diagnostic genetic markers here. DNA template

concentrations: $20,2,0.2,0.02,0.002,0.0002,0.00002$. a HvOs03g14380_G125A. b Hv11_11299. c HvANT2_C4289T. d HvPPDH1_A $2721 \mathrm{G}$. e Hv11_10933_GC. f Hv11_10818_CA. g HvOs02g01490_G607 A. h HvCly1_A2604 G. i HvVRNH1_SNP2

effectiveness of allele calling when two contrasting alleles were present in the DNA template was investigated. DNAs from 'Pelican' and 'Felicie', which contrast for each of the eight DUS traits under investigation, were mixed in nine different proportions as shown in Table 2. These DNA mixtures were used as template for genotyping using the diagnostic KASP genetic markers so that each assay contained a total of $20 \mathrm{ng}$
DNA template. The genetic markers were evaluated in four technical replicates for each of the 15 DNA templates investigated, and the results shown in Fig. 2. All nine diagnostic KASP markers were found to be codominant, i.e. able to detect both alleles when they are present in equal concentrations in the template (DNA templates containing $10 \mathrm{ng}$ 'Felicie' and $10 \mathrm{ng}$ 'Pelican' DNA). Similarly, all nine KASP markers were able to 
Table 2 'Felicie' and 'Pelican' barley DNA used as template per KASP reaction. Each of the nine templates represent 'Felicie' DNA spiked with increasing quantities of DNA from the contrasting variety 'Pelican'. A total of $20 \mathrm{ng}$ template was used for all genotyping reactions

\begin{tabular}{lll}
\hline $\begin{array}{l}\text { DNA template } \\
\text { number }\end{array}$ & $\begin{array}{l}\text { ng DNA per } \\
\text { KASP reaction, } \\
\text { Felicie versus } \\
\text { Pelican }\end{array}$ & $\begin{array}{l}\text { Percentage } \\
\text { DNA present } \\
\text { in samples }\end{array}$ \\
\hline 1 & $20: 0$ & $100 \%$ Felicie \\
2 & $19.98 / 0.02$ & $99.9 \%$ Felicie, $0.1 \%$ Pelican \\
3 & $19.8 / 0.2$ & $99 \%$ Felicie, $1 \%$ Pelican \\
4 & $16 / 2$ & $90 \%$ Felicie, $10 \%$ Pelican \\
5 & $10 / 10$ & $50 \%$ Felicie, $50 \%$ Pelican \\
6 & $2 / 18$ & $10 \%$ Felicie, $90 \%$ Pelican \\
7 & $0.2 / 19.8$ & $1 \%$ Felicie, $99 \%$ Pelican \\
8 & $0.02: 19.98$ & $0.1 \%$ Felicie, $99.9 \%$ Pelican \\
9 & $0: 20$ & $100 \%$ Pelican \\
\hline
\end{tabular}

detect contamination levels of $10 \%$ (18 ng versus $2 \mathrm{ng}$ ), irrespective of which variety represented the allele at low concentration.

Detection of DUS off-types in bulk DNA extractions from multiple individuals

Having shown the sensitivity of diagnostic genetic markers selected for study to detect DUS off-types using in vitro admixture, we next investigated the ability of the markers to detect DUS off-types in bulk DNA extractions from multiple individuals. Given the in vitro sensitivity limit was $10 \%$, tissues sampled from individual 'Felicie' and 'Pelican' seedlings were sampled and bulks of 10 samples used for DNA extraction. Bulks contained varying proportions of 'Felicie' and 'Pelican' tissue, the first with 10 'Felicie' samples, and each subsequent bulk consisting of one less 'Felicie' sample and one more 'Pelican' sample, with the final bulk representing 10 'Pelican' samples (Supplementary Table 2). Genotyping with these templates found seven markers to robustly detect the presence of a single offtype in a bulk, irrespective of which allele was present at the lower frequency: HvOs03g14380_G125A, Hv11_11299_GC, HvANT2_C 4289 T, Hv11_10933_GC, Hv11_10818_CA, HvOs02g01490_G60, HvCly $\overline{1}_{-} \mathrm{A} 2604 \overline{\mathrm{G}}$ and HvVRNH1_SNP2 (Supplementary Fig. 1). However, while the remaining marker (HvPPDH1_A2721G) was able to consistently detect a single 'Pelican' individual within a bulk of 10, it was not able to detect a single 'Felicie' individual within a bulk for all three replicates undertaken, as the allele call for one rep for this template clustered with allele calls from 'Pelican' DNA template.

\section{Discussion}

The use of diagnostic genetic markers for DUS evaluation

Development of new plant varieties represents a longterm investment for breeders, typically 10-15 years. This level of investment is protected via the awarding of plant breeders' rights, which is based on DUS testing in countries and regions that are signatories to the UPOV system. If a newly developed submission to variety testing fails the DUS process, the investment in its development is lost. For this reason, demonstration that molecular markers might be relevant to processes relating to DUS testing is of ongoing interest to plant breeders and UPOV testing stations around the world. For the intellectual property vested in a new variety to be protected, it must first be clearly defined (Jones et al. 2013a). According to UPOV guidelines, a variety is 'defined by its characteristics and that those characteristics are therefore the basis on which a variety can be examined for DUS' (UPOV 2002). Currently, DUS testing is carried out using a suite of phenotypic characters to compare new candidate varieties with relevant existing varieties. A positive DUS test will result in a formal and official description of the candidate variety using its relevant characteristics (Jones et al. 2013a). Advances in genotyping platforms and reductions in their cost of use provide opportunities for their potential application in variety registration (Jones et al. 2013b; Jamali et al. 2019). Recognising this potential, the Biochemical and Molecular Techniques (BMT) Working Group of UPOV outlines three possible models for the use of molecular markers for DUS testing (UPOV 2011): Model 1 involves the use of molecular markers to directly predict phenotypic DUS characters; Model 2 involves calibration of threshold levels of molecular distinctness with those attained using traditional DUS traits to discriminate between varieties, while Model 3 involves the development of a new molecular-based system independent of phenotypic traits. Here, we investigate Model 1 specifically the potential for using 

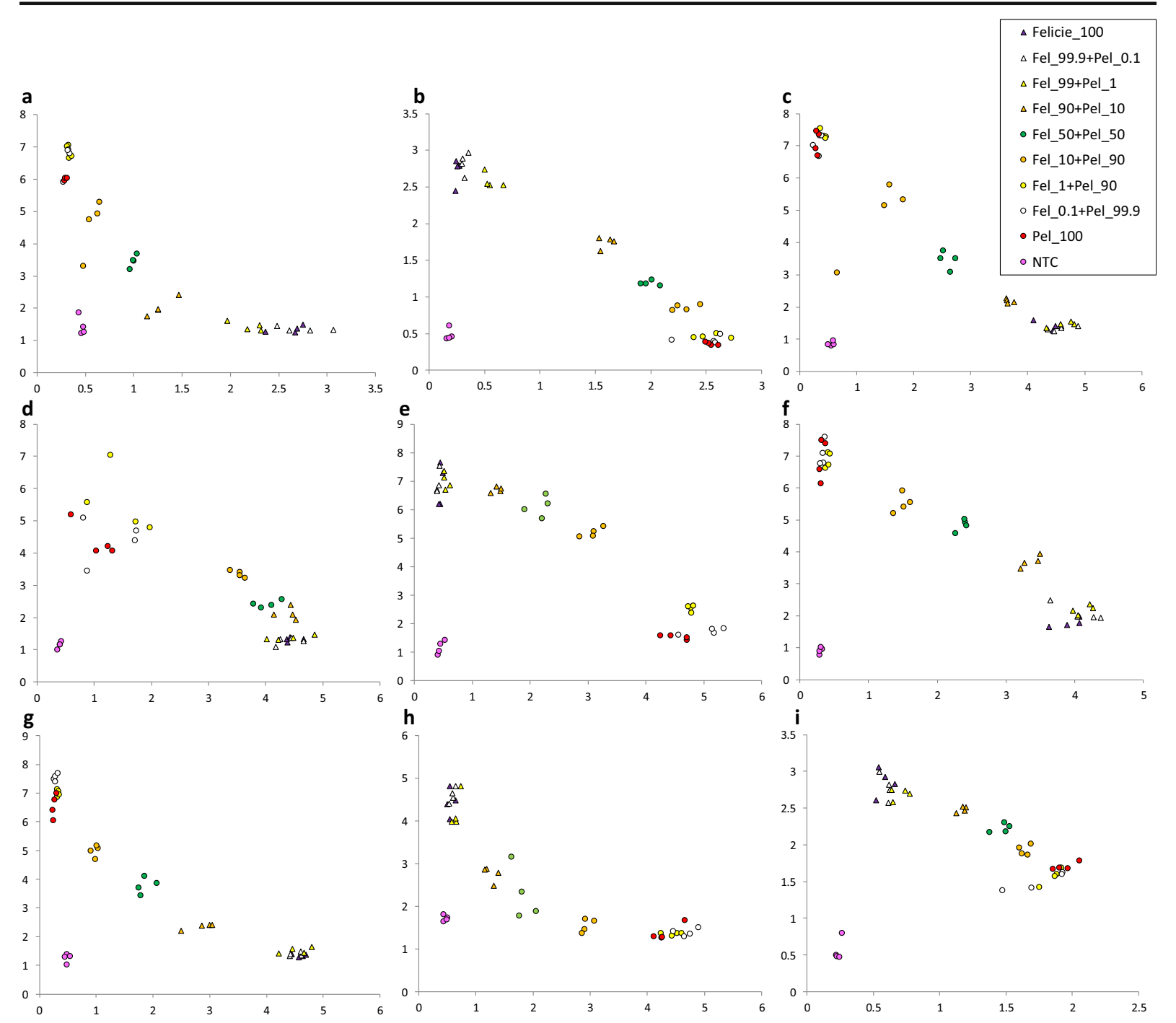

Fig. 2 Use of diagnostic KASP markers to detect in vitro DUS off-types using DNAs spiked at different concentrations with DNA of a contrasting variety (see Table 2). Pel = cv 'Pelican'. $\mathrm{Fel}=\mathrm{cv}$ 'Felicie'. NTC $=$ no DNA template control. $X$-axis: FAM fluorescence. $Y$-axis: VIC fluorescence. KASP markers assessed: a

HvOs03g14380_G125A. b Hv11_11299_GC. c HvANT2_C4289T. d HvPPDH1_A2721G. e Hv11_10933_GC. f Hv11_10818_CA. g HvOs02g01490_G607A. h HvCly1_Ā2604G. i HvVRNH1_SNP2 molecular markers diagnostic for specific DUS traits for the assessment of uniformity within the DUS context. In barley, we have previously shown that it is possible to identify diagnostic or perfect genetic markers for many barley DUS traits (Cockram et al. 2009, 2010, 2012, 2015; www.naib.com/mas/). However, while these have been shown to be relevant to assessing distinctness (D) and stability (S), to date, the use of barley markers in assessing uniformity (U) had not been shown. In barley, the ability to detect DUS off-types from DNA extracted from a given sample of grains would rely on the diagnostic genetic markers used being sensitive enough to be able to detect DNA variants, such as SNPs, when they are present in DNAs (a) at low concentration, and (b) as a mixture of alleles. Here, we find the tested molecular assays diagnostic for an array of barley DUS traits are able to reliably detect DUS off-types at frequency of 1 in 10 using DNA extracted from tissue collected from pools of 10 individuals. Thus, using the KASP genotyping system, we demonstrate the potential use of genetic 
markers for the characterisation of uniformity within the context of DUS assessment. The methodology should also be of use in other applications where detection of off-types is required. We note that the vast majority of barley varieties released represent inbred lines. In the context of inbreds, if a candidate variety was submitted in which one or more of the 10 seed tested were heterozygous at the candidate locus, based on the results presented here we may not expect the appropriate DNA bulk to be detected, as an off-type DNA proportion of $5 \%$ has not been tested.

Practical use of molecular markers for the assessment of uniformity within a DUS context

The acceptable thresholds for barley uniformity depend on which character is being assessed (UPOV TG 19/10 and CPVO-TP/019/4). For 'B' characteristics (commonly those recorded in field plots) in a sample of 2000 plants, a maximum of 5 off-types are permitted. ' $A$ ' characteristics (mostly recorded on samples harvested from the plot) in a sample size of 100 the threshold is 3 off-types. As DNA extractions from bulks of seed are not normally of sufficient quality to use for DUS offtype detection, the most practical and reliable method to implement the markers investigated here would be to germinate batches of seed, and to extract bulk DNAs from leaf tissue sampled from 10 seedlings. For example, in stage 1, 100 seeds could be germinated (or samples taken from the growing trial) and leaf samples from 10 batches of 10 seed used for DNA extraction, taking $\sim 5$ days in total. Each DNA sample would then be used as a template for KASP genotyping, with 3 technical replicates per DNA sample (equating to 30 KASP reactions per KASP marker), followed by dataanalysis (2 days). Allowing for the inclusion of the 15 serial dilution control DNAs in four replicates (60 reactions) plus 12 negative controls, this would allow 4 diagnostic KASP markers to be assayed per 384-well plate (Fig. 3). The whole process could be undertaken in 7 days using approximately 1.5 days of technician time, at which point seed batches with $3 \%$ or more DUS offtypes would be determined. This would be a particularly effective technique for the assessment of the DUS traits 'aleurone layer colouration' or 'hairiness of basal leaf sheaths', both of which are labour intensive. A saving could also be made for the assessment of 'seasonal growth type', which requires an entire trial to determine (although numbers of plants assessed would need to be adjusted to meet protocol requirements). If further investigation to precisely determine the number of DUS off-types was required, a stage 2 experiment could subsequently be carried out: DNAs would be extracted individually from each of the original 100 seedlings sampled in the previous experiment, and the relevant KASP marker used to genotype all 100 individuals. As the complexity of the DNA template is low at this point, only 1 rep would be needed per individual. Thus, stage 2

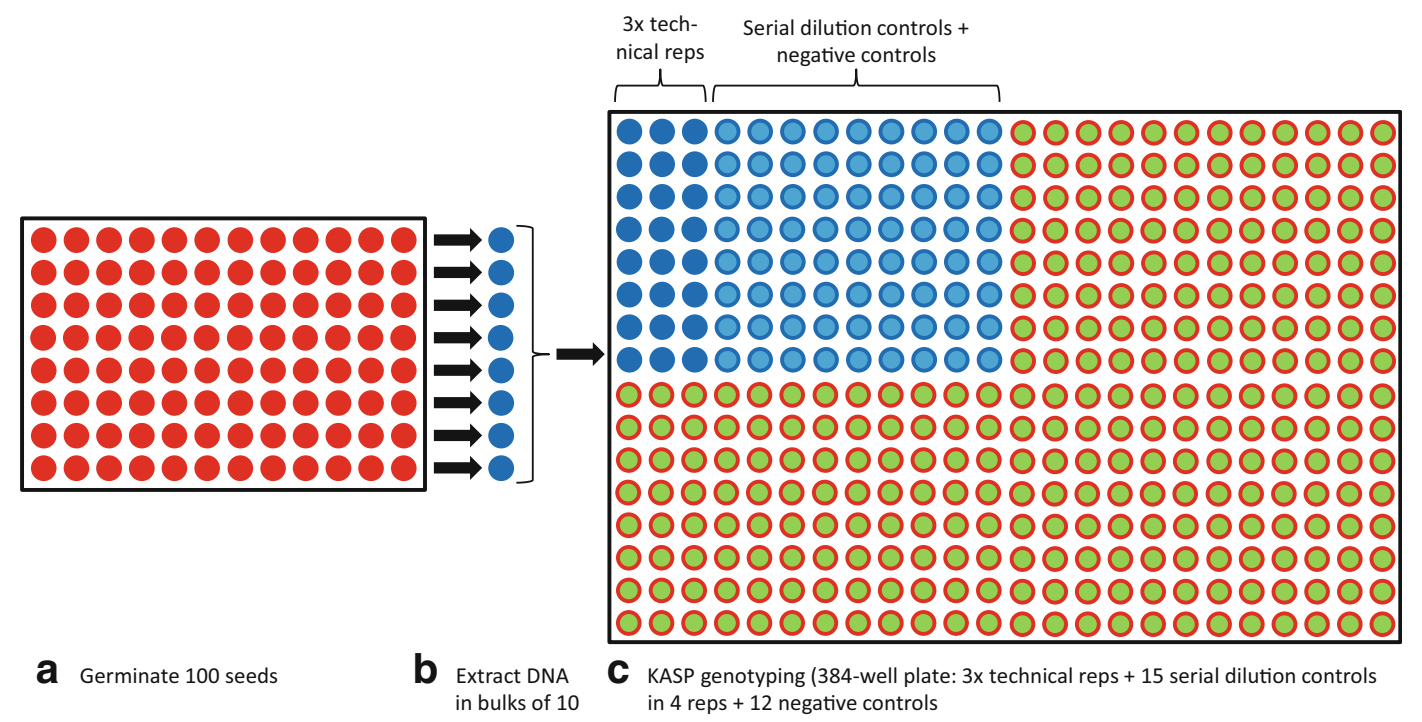

Fig. 3 Proposed pipeline for molecular testing for DUS off-types in batches of 100 barley seed. In step 3, positions within a single 384-well plate required to assay one KASP marker are indicated in blue. Therefore, at step C, four KASP markers could be assayed in a single 384-well plate, and results would be visualised allowing DNAs containing DUS off-types to be identified 
would require 112 reactions per diagnostic KASP marker investigated (including 2 controls in 4 technical replicates each, plus 4 water controls). It should be noted that this approach requires that the underlying genetic variants controlling the target DUS trait of interest are known. In barley, while some of these are already known (summarised by Cockram et al. 2010, 2012; Jones et al. 2013a), implementation under the UPOV Model 1 approach would require the relevant genetic variants for all DUS traits to have been determined. However, it is possible that for traits that are difficult or time consuming to score, such as 'hairiness of leaf sheaths' (UPOV Trait 3), it could be beneficial to employ molecular DUS techniques on a trait by trait basis.

\section{Future prospects}

Taken together, these results indicate that the major limiting factor for wider application of this proof-ofprinciple for the assessment of uniformity in barley within the DUS context is the availability of diagnostic genetic markers for additional DUS traits. The ongoing development of genotyping methodologies in barley that assay increasingly larger number of genetic variants, such as the barley whole-exome capture array (Mascher et al. 2013) and genotyping by sequencing (Poland et al. 2012), means that it should soon be possible to identify tightly linked, or causative, genetic polymorphisms that underlie many more barley DUS traits. Assuming this is possible, implementation would ultimately rely on cost-benefit analysis and consensus around the modification of guidelines that govern variety accreditation.

Author contributions DO'S sourced funding; DO'S, BS and JC designed research; BS performed lab work; DO'S, JC and MW provided project resources and undertook project management; BS and JC wrote the manuscript; all authors reviewed and edited the manuscript.

Funding information This work was funded by Department for Environment, Food and Rural Affairs (Defra) grant $2011 \mathrm{~K}$.

\section{Compliance with ethical standards}

Conflict of interest The authors declare that they have no conflict of interest.
Open Access This article is licensed under a Creative Commons Attribution 4.0 International License, which permits use, sharing, adaptation, distribution and reproduction in any medium or format, as long as you give appropriate credit to the original author(s) and the source, provide a link to the Creative Commons licence, and indicate if changes were made. The images or other third party material in this article are included in the article's Creative Commons licence, unless indicated otherwise in a credit line to the material. If material is not included in the article's Creative Commons licence and your intended use is not permitted by statutory regulation or exceeds the permitted use, you will need to obtain permission directly from the copyright holder. To view a copy of this licence, visit http://creativecommons.org/licenses/by/4.0/.

\section{References}

Cockram J, Chiapparino E, Taylor SA, Stamati K, Donini P, Laurie DA, O'sullivan D (2007a) Haplotype analysis of vernalization loci in European barley germplasm reveals novel $V R N$ $H 1$ alleles and a predominant winter $V R N-H 1 / V R N-H 2$ multilocus haplotype. Theor Appl Genet 115:993-1001

Cockram J, Mackay IJ, O'Sullivan DM (2007b) The role of double-stranded break repair in the creation of phenotypic diversity at cereal VRN1 loci. Genetics 177:1-5

Cockram J, Norris C, O’Sullivan DM (2009) PCR markers diagnostic for seasonal growth habit in barley. Crop Sci 49:403410

Cockram J, White J, Zuluaga DL, Smith D, Comadran J, Macaulay M, Luo Z, Kearsey MJ, Werner P, Harrap D, Tapsell C, Liu H, Hedley PE, Stein N, Schulte D, Steuernagel B, Marshall DF, Thomas WT, Ramsay L, Mackay I, Balding DJ, AGOUEB Consortium, Waugh R, O'Sullivan DM (2010) Genome-wide association mapping to candidate polymorphism resolution in the un-sequenced barley genome. Proc Natl Acad Sci U S A 107:21611-21616

Cockram J, Jones H, Norris C, O'Sullivan DM (2012) Evaluation of diagnostic molecular markers for DUS phenotypic assessment in the cereal crop, barley (Hordeum vulgare ssp. vulgare L.). Theor Appl Genet 125:1735-1749

Cockram J, Soh E-H, Norris C, O’Sullivan D (2015) Molecular and phenotypic characterization of the alternative seasonal growth habit and flowering time in barley (Hordeum vulgare L.). Mol Breed 35:1-11

Distelfeld A, Tranquilli G, Li C, Yan L, Dubcovsky J (2009) Genetic and molecular characterization of the VRN2 loci in tetraploid wheat. Plant Physiol 149:245-257

Franckowiak JD (1995) Notes on linkage drag in Bowman backcross derived lines of spring barley. Barley Genet Newsl 24: 63-70

Fulton TM, Chunwongse J, Tanksley SD (1995) Microprep protocol for extraction of DNA from tomato and other herbaceous plants. Plant Mol Biol Report 13:207-209

Hemming MN, Fieg S, Peacock WJ, Dennis ES, Trevaskis B (2009) Regions associated with repression of the barley (Hordeum vulgare) VERNALIZATION1 gene are not required for cold induction. Mol Gen Genomics 282:107-117 
Jamali SH, Cockram J, Hickey LT (2019) Insights into deployment of DNA markers in plant variety protection and registration. Theor Appl Genet accepted

Jones H, Norris C, Cockram J, Lee D (2013a) Variety protection and plant breeders' rights in the 'DNA era'. In: Lübberstedt T, Varshney RK (eds) Diagnostics in plant breeding. Springer, Dordrecht, pp 396-402

Jones H, Norris C, Smith D, Cockram J, Lee D, O'Sullivan DM, Mackay I (2013b) Evaluation of the use of high density SNP genotyping to implement UPOV Model 2 for DUS testing in barley. Theor Appl Genet 126:901-911

Karsai I, Szüucs P, Mészáros K, Filichkina T, Hayes PM, Skinner JS, Láng L, Bedö Z (2005) The Vrn-H2 locus is a major determinant of flowering time in a facultative $\mathrm{X}$ winter growth habit barley (Hordeum vulgare L.) mapping population. Theor Appl Genet 110:1458-1466

Komatsuda T, Pourkheirandish M, He C, Azhaguval P, Kanamori $\mathrm{H}$ et al (2007) Six-rowed barley originated from a mutation in a homeodomain-leucine zipper I-class homeobox gene. Proc Natl Acad Sci U S A 104:1424-1429

Lundqvist U, Franckowiak J, Konishi T (1996) New and revised descriptions of barley genes. Barley Genet Newsl 26:22-43

Lundqvist U, Franckowiak JD, Konoshi T (1997) New and revised descriptions of barley genes. Barley Genet Newsl 26:22-516

Mascher M, Richmond TA, Gerhardt DJ, Himmelbach A, Clissold L, Sampath D, Ayling S, Steuernagel B, Pfeifer M, D'Ascenzo M, Akhunov ED, Hedley PE, Gonzales AM, Morrell PL, Kilian B, Blattner FR, Scholz U, Mayer KF, Flavell AJ, Muehlbauer GJ, Waugh R, Jeddeloh JA, Stein N (2013) Barley whole exome capture: a tool for genomic research in the genus Hordeum and beyond. Plant J 76:494-505

Nair SK, Wang N, Turuspekov Y, Pourkheirandish M, Sinsuwongwat S, Chen G, Sameri M, Tagiri A, Honda I, Watanabe Y, Kanamori H, Wicker T, Stein N, Nagamura Y, Matsumoto T, Komatsuda T (2010) Clistogamous flowering in barley arises from the suppression of micro-RNA guided HvAP2 mRNA cleavage. Proc Natl Acad Sci U S A 107: 490-495

Poland JA, Brown PJ, Sorrels ME, Jannink J-L (2012) Development of high-density genetic maps for barley and wheat using a novel two-enzyme genotyping-by-sequencing approach. PLoS One 7:e32253
Ramsay L, Comadran J, Druka A, Marshall DF, Thomas WTB, Macaulay M, MacKenzie K, Simpson C, Fuller J, Bonar N, Hayes PM, Lundqvist U, Franckowiak JD, Close TJ, Muehlbauer GJ, Waugh R (2011) INTERMEDIUM-C, a modifier of lateral spikelet fertility in barley, is an ortholog of the maize domestication gene TEOSINTE BRANCHED 1. Nat Genet 43:169-172

Szücs P, Skinner J, Karsai I, Cuesta-Marcos A, Haggard KG, Corey AE, Chenn THH, Hayes PM (2007) Validation of the $V R N-H 2 / V R N-H 1$ epistatic model in barley reveals that intron length variation at $V R N-H 1$ may account for a continuum of vernalization sensitivity. Mol Gen Genomics 277: 249-261

Trevaskis B (2010) The central role of the VERNALIZATIONI gene in the vernalization response of cereals. Funct Plant Biol 37:479-487

UPOV (1991) International convention for the protection of new varieties of plants. International Union for the Protection of new varieties of plants, Geneva (online). Available at: http://www.upov.int/upovlex/en/conventions/1991/act1991. html. Accessed 26 Nov 2018

UPOV (2002) TG/1/3 General introduction to the examination of distinctness, uniformity and stability and the development of harmonized descriptions of new varieties of plants. International Union for the Protection of new varieties of plants, Geneva. (online) Available at: http://www.upov. int/resource/en/introduction_dus.html. Accessed 26 Nov 2018

UPOV (2011) INF/18/1 Possible use of molecular markers in the examination of distinctness, uniformity and stability (DUS). International Union for the Protection of New Varieties of 1215 Plants, Geneva. (online) available at: http://www.upov. int/edocs/infdocs/en/upov_inf_18_1.pdf. Accessed 26 Nov 2018

Yan L, Loukoianov A, Blechl A, Tranquilli G, Ramakrishna W, SanMiguel P, Bennetzen JL, Echenique V, Dubcovsky J (2004) The wheat VRN2 gene is a flowering repressor downregulated by vernalization. Science 303:1640-1644

Publisher's note Springer Nature remains neutral with regard to jurisdictional claims in published maps and institutional affiliations. 